\title{
Editorial
}

\section{Humanities - To Be or Not To Be, That Is the Question}

\author{
Albrecht Classen \\ Department of German Studies, University of Arizona, Tucson, AZ 85721, USA; \\ E-Mail: aclassen@u.arizona.edu
}

Received: 7 September 2011 / Accepted: 12 September 2011 / Published: 16 September 2011

\section{Introduction}

Let us carry some proverbial owls to Athens or coals to Newcastle, that is, revisit issues that have been discussed and examined by so many different voices in the past and the present. However, those issues by themselves are so powerful and important, so urgent and difficult that we must never tire of examining them always anew because they pertain centrally to our own human existence and prove to be the defining factors for our survival as a species. Why do we need the humanities as an academic discipline in the university, or in our educational system at large? What role do the humanities play both inside and outside the academy? Most universities in this world somehow acknowledge the importance of languages, literatures, music, art history, philosophy, religion, and education. But when it comes to basic financial issues, the humanities tend to be the first victims of budget cuts, if we disregard specifically liberal arts colleges that focus on the humanities above all or exclusively.

Lamentably, it is always an easy method by politicians and bureaucrats to pay lip service to the humanities, yet when they face tough choices, they regularly opt to favor the hard sciences, economics, business, mathematics, medicine, and athletics. I include athletics because I teach at an US-American institution, where athletics departments commonly prove to be the biggest money makers, irrespective of their low or non-existing academic relevance. There is nothing negative about athletics, or any kind of sport activities, especially in an intellectual context insofar as the Romans already knew of the significance of a healthy body as the critical foundation for a healthy mind. Juvenal (first to second century C.E.) emphasized in his Satires (X) the need to have a mens sana in coropore sano (a healthy mind in a healthy body) [1]. But that is very much beside our point here. More important now proves to be how to create this healthy mind, once the body has been made healthy. At stake proves to be the correlation between both dimensions, since they are interdependent. By the same token, that applies to the relationship between the humanities and the sciences, for example. 


\section{Humanities and University}

It would be difficult to argue against those who point out the needs for all universities to secure the basic finances, that is, a solid budget, either from public or private funds. Moreover, there is the common assumption, rightly or wrongly, that studying the sciences or business will easily lead to professional employment after the completion of ones's academic training. It seems highly unlikely that those who turn toward the study of medicine might easily face unemployment after their graduation. Altogether, our society is in desperate need of medical doctors, of engineers, scientists, and business leaders. The technological changes require ever more engineers and computer experts, and since food and water are some of the most burning issues in this world, no one would question the overarching importance of agriculturists, hydrologists, or chemists. Yet, what does someone do with an education in the humanities?

To begin with our discussion, a true university in the Humboldtian sense does not narrowly define itself as a professional training school [2]. By contrast, the university educates, offers Bildung, and serves as a place where teaching and research go hand in hand in the free spirit of the intellect, aiming for the improvement of the individual, the community, and the nation, if not the world [3]. The humanities play a central role in that context, as most universities, at least in North America and Europe, include the liberal arts as one of the essential corner stones. I venture to claim that a central ideal at a modern university would be to help the young people enrolled as students to gain a wellrounded education, which includes both scientific-mathematical and humanistic aspects. As individuals, we need the abilities to speak and to write, to count and to calculate, to analyze and to think, to appreciate and to understand, to emphasize and to sympathize, to share and to ask, to collaborate and to teach.

The Middle High German poet Wolfram von Eschenbach expressed this perhaps the best in his classic Grail romance, Parzival (ca. 1205), where the suffering in the world, represented by the Grail King Anfortas's wound in the testicle, is finally overcome by the protagonist, Anfortas's nephew Parzival, who simply has to formulate the one basic question: "Uncle, what troubles you?" [4]. Parzival has learned true commiseration, has understood that all people belong to one community, and that pity, empathy, and sympathy are the glue that holds us all together. Most significantly, the young protagonist has broken into tears while asking for the direction to reach the Grail, and God then grants Anfortas the immediate recovery from near death. Subsequently, the Grail stone has a writing appear on its surface which announces Parzival as the legitimate heir and successor to the throne, who is soon joined by his wife Condwiramurs and their two sons, whom he had not seen for years. Love thus reenters the human heart, and global healing sets in. There is no doubt that humanity is plagued by sorrow and suffering, but love and joy can always compensate the worst experiences, there is hope, as poets and artists have told us for ages. It is the task of the humanities scholars to bring out that message and to carry it forth to the world.

\section{A Homesick Astronaut}

Now, let us turn to the example of an astronaut who spends a long time in space, visiting the space station, the moon, or a nearby planet, such as Mars. The astronaut can only accomplish his or her task because a huge team of researchers and technicians at ground control support everything s/he does out 
there, far away from mother Earth. Considering the complexity of the entire space program and the space ship, the individual astronaut almost seems to be nothing but a cog in the wheel, whether s/he steers the space ship himself or not. At any rate, even though the astronaut can accomplish all his tasks, reach the distant stellar body, and traverse unimaginable distances, ultimately, however, he remains, we hope, a human being. While s/he is floating through space, working, eating, sleeping, occasionally exercising, something is happening for sure which the official reports normally never mention. The astronaut has also a mind, a heart, fantasy, dreams, hopes, and fears. No one at ground control will ever assist him/her in coming to terms with his/her own individual existence while s/he floats quietly through dark space, having the glowing body of the moon, of Mars, or of Earth in front of his/her eyes. And once s/he has returned and gotten out of the space suit, the astronaut retransforms into the being that $\mathrm{s} / \mathrm{he}$ had been before, man or woman.

What might go through his/her mind while s/he is traveling in space? The astronaut is a human being, and all human beings have feelings of all sorts, and cannot be separated from those easily, if ever at all. Here the humanities suddenly come into play, and they prove to be essential. Without artistic expressions (music, literature, visual arts, etc.), the human creature would not be what it is in essential terms. Simply put, we need all those hard sciences, business, economics, medicine, etc., but by the same token we also need songs, poems, romances, paintings, sculptures, films, and all kinds of other art works and media, including dance, theater, etc. Why would the astronaut want to return to earth if s/he would not know that human society would wait for him/her down there, whatever that might mean in specific terms. Space flight might encapsulate perfectly why the humanities are one of the central subjects in our lives. Astronautical efforts might achieve great things, and they have actually done so many times, to the awe of mankind. But beyond that, what has space travel achieved for the improvement of the human soul? The question is unfair, of course, because astronautical endeavors have very specific scientific goals, and they should not aim for humanistic goals when it is all technical in the entire set-up. However, if we focus only on one side in our lives, we will be blinded, for sure. This also means that those who only consider poetry or music as the mantra of everything, ignoring the essential aspects of the sciences and medicine that have done miracles to the improvement of human life, blatantly commit the same mistake as those who want to get rid of the humanities.

Recently I had the wonderful opportunity to attend an art opening displaying the paintings and metal art work by the East German artist Andreas Nottebohm [5]. He has been one of the artists whom NASA had commissioned to reflect upon the space program by means of art works. Indeed, many of his contributions can rightly be called masterpieces, offering innovative perspectives toward space exploration, and providing visual lenses for the stunning beauty of the universe. Nottebohm achieved the most remarkable accomplishment of working on the aesthetic and the scientific side, thus addressing both the scientists and the ordinary people interested in art. More importantly, he created images of the extraterrestrial world making it thus accessible through visual means.

What does art, what does music bring about, and why would they be important for all people? Of course, there might not be any need to raise such questions, but let us repeat them anyway because each person, every generation, and all people have to deal with them over and over again in order to come to terms with their own idiosyncratic culture and their value system, that is, with their essential being. We must also expand the questions and include literature/poetry, philosophy, and religion, to 
mention the most important domains. The universe in its microcosmic and macrocosmic dimensions is, ultimately ineffable and inconceivable in specific human terms, and we often stand in front of a natural phenomenon, deeply filled with admiration, love, and delight, sometimes also with fear and horror, and yet we cannot vocalize specifically what happens with us or what it all matters to us as creatures in the universal context. The same might happen with man-made objects, machines, bridges, buildings, or clothing. The inner beauty, brought to light by human ingenuity, is suddenly laid bare to us, and we feel an inner stirring, sometimes translating into poetry, sometimes rendered as a musical composition or an art piece. The apophatic character of the absolute beautiful challenges us in many respects, since we cannot tolerate, as human beings, the lack of words for what we experience in physical and metaphysical terms. No wonder that the world of medieval mystical literature proves to be so amazing even for us today because these religious authors had already gained incredible insights into the Godhead and had formulated their visions and revelations in most extraordinary fashion.

\section{Beauty}

Let me illustrate some of those fundamental features with a brief discussion of the old Alpine pass Tremola, leading over the St. Gotthard, Switzerland [6]. Road engineers created sone of the most stunning switchbacks and serpentine roads crossing the massive mountain, providing a means of transportation in some of the most rugged Swiss terrain. Human skills and abilities made it possible to defy the mountain's challenge and to allow people to drive over the pass, and this already for a long time, though the first major modern road construction was not completed until 1967 [7]. All that belongs in the field of history and road engineering. But one look at that mountain side alone easily leaves anyone simply breathless.

The beauty of the rocky landscape in lofty heights is incomparable and requires more than a technician's mind to grasp its full meaning. A poet might be helpful, then a photographer, and a composer would certainly be a good companion here as well. A painter could do wonders, just as the engineer did when he created those hairpin curves. However, as a religious person would point out, the creator of all that beauty also deserves credit, probably the greatest of them all. However we might see that, and irrespective of what beautiful part of this world we might consider in this context, whether glaciers in Alaska or a black-sand beach on the Big Island of Hawai'i, natural beauty strikes us as profound and all encompassing, perhaps in the sense Ralph Waldo Emerson (1803-1882) had already described it so powerfully, especially in his essay "The Over-Soul" (1841): "We live in succession, in division, in parts, in particles. Meantime within man is the soul of the whole; the wise silence; the universal beauty, to which every part and particle is equally related, the eternal ONE. And this deep power in which we exist and whose beatitude is all accessible to us, is not only self-sufficing and perfect in every hour, but the act of seeing and the thing seen, the seer and the spectacle, the subject and the object, are one. We see the world piece by piece, as the sun, the moon, the animal, the tree; but the whole, of which these are shining parts, is the soul." [8]

We need this realization so desperately since life without beauty is very hard to take and probably not possible. Even the foulest and most destroyed area in inner cities or in industrial regions are not devoid of beauty, whether we think of Manchester, UK, Essen, Germany, or Pittsburgh, PA (with apologies to those cities, if my assessment is completely incorrect). But who perceives that beauty, and 
who can help the individuals living there to recognize those hidden treasures? Let us move more closely to human life itself by extending the same line of thoughts. Beauty is not limited to the young female beauty queen. The old grandmother, beloved by her children and grand-children, can exude more spiritual beauty than the most stunning star model in her physical appearance but coupled with limited emotional maturity. One of the best examples illustrating the inner beauty of an old person was proved by the famous German Renaissance artist Albrecht Dürer when he created a woodcut of his old mother in 1514 [9].

We all know that we will grow old and die, and this sometimes at the very moment when the entire world seems to be at our disposal and we enjoy beauty to the utmost, as we learn so well in Goethe's famous play Faust (with the second part finally completed in 1831) [10]. His contract with Mephistopheles, or the devil, stipulates, upon his own insistence, that the latter could take his soul when the one unlikely moment would have arrived: “Ah, stay a while! You are so lovely!" (Scene IV, verse 1700) [11]. The only thing we do not know is the time when we will die. Until then, however, we have every chance to prepare ourselves, to work toward that moment, and try hard to make the best out of the short span of time granted to us here on earth. This labor should be a labor of love. We ought to find love, to make friends, to help society, and leave this world behind as a better place, whatever there might be in our power as an individual. The value, for instance, of an unexpected smile or hug cannot even be defined in concrete terms. Poets, however, would know how to say what such a smile really means.

\section{Science and Technology and Human Nature}

While the sciences and medicine are most important factors in this huge enterprise which every individual has to go through from birth to death, we cannot only rely on material strategies that contribute to the basic maintenance of human life. After all, we are both physical and emotional/spiritual beings. We love and hope, we laugh and cry; we have hopes and we can despair; we are filled with anger and with joy; we respond to the external world with enthusiasm and melancholy; we might live in a deeply satisfying partnership with a beloved person, or we might face loneliness and boredom all by ourselves. The possibilities of how our lives develop are infinite, and each person here on earth has to cope with the external and internal conditions which are given us. Some become fighters, others are passive figures. Some people are warriors, others pursue peace at almost any cost. In other words, the options are endless, and the changes that can occur in our lives are most promising and threatening at the same time.

Nothing what I have said will really come as a surprise. We can read about all those aspects in selfhelp books, in meditation guides, we can hear about them in sermons, but then also in poems, in theater plays, in movies, in radio talk shows, in confessionals, in discussions with friends and lovers, in debates with counselors and advisors, etc. In this context a number of factors immediately emerge that are essential in comprehending the issues at stake. We as human beings rely most critically on the ability to communicate with each other, either by means of words, gestures, images, music, or by way of written texts, images, and sound. We are, after all, citizens of one world in all its kaleidoscopic features and must rely on each other, trust each other, if possible at all, to make sure that the ideas and insights from the past carry over to the future and so guarantee the survival of our planet Earth - there 
is no other (see Martha Nussbaum's brilliant appeals and reflections on the essential function of the humanities) [12]. Moreover, human life is determined by the experiences of love, happiness, joy, and death. Sorrow is always paired with hope. We can dream and hope for a better life and imagine a utopian society. Dr. Martin Luther King, Jr. was so right about that when he pronounced that he had a dream [13]. In fact, in order to live we all must dream and aspire for a better world in which we can realize all our potentials and abilities. Some might achieve that goal, others might be only partially successful, and others again might fail. Nevertheless, the central issue proves to be the strife itself, which seems to be tantamount to life.

However, is there any way to define what these fundamental aspects in our lives might be? Can we define love, or death, joy or God? Is there any possibility to specify what the basic emotional experiences truly are, perhaps by means of a mathematical or chemical formula? Both medieval and modern poets have struggled in vain to achieve that goal, and scientists have never even claimed that they might be able to answer those questions in the affirmative. In general, I would assume that the arts and literature, whether composed and created in East or in West, in antiquity or in the present, are best qualified to help the individual to come to terms with some of those issues that are so important for us if we want to enjoy a 'good life,' whatever that might mean in specific terms. Who would deny the soothing, uplifting, enthralling, empowering, saddening, and illuminating power of music? As much as we always fight over what might constitute good or bad literature, paintings, sculptures, etc., we would probably all agree on the one common experience that the ineffable features in human existence find the most appropriate formulation in poetic, visual, or musical form. This is the domain of the humanities, and whoever tries to cut down that academic field is also announcing open warfare against human culture and human life.

\section{Our Common Humanities}

Studying the humanities means many different things, such as developing linguistic skills to reach out to other people and other cultures. By way of literary works we can understand differences in religious orientation and political viewpoints. Music and paintings have always spoken a universal language, building bridges where gulfs and abysses seem to separate everyone in hostility and enmity. Of course, the same applies to mathematical numbers and chemical formulas, which also prove to be of extreme importance. All languages, including those used to develop computers and internet connections, reach out to other people. The humanities, however, are primarily qualified to establish those links between individuals and communities, and to create the essential means to overcome conflicts and wars. By the same token, the study of literary works or art works has never prevented the outbreak of hostilities, but neither have physical or economic research.

Even when humanists do not succeed in reaching out to the other creatures here in this world, and cannot convince the other side to put down the weapons, they are the ones who carry the torch of love and peace across all barriers, through all cultures, and beyond all linguistic hurdles. Ironically, the economic impact of those humanistic efforts is so great that no one can even fathom the full extent. We might ultimately say that the humanities have defended themselves rather weakly, although they represent some of the most central and most important issues in this world. It would be absurd to set up an artificial polarity with the sciences because those are like brothers and sisters to the humanities, 
as perhaps best illustrated by the differences and yet also strong familial bonds between Alexander (1769-1859) and Wilhelm Humboldt (1767-1835), the first having been one of the greatest scientists of his time, while the other one established the modern university and laid the foundation of the humanities as we know them today.

Irrespective of all the military conflicts between Muslim fundamentalists and the western world today, and irrespective of the many Crusades by the Christian knights against the Muslims holding the Holy Land during the Middle Ages, the West owes much of its present scientific, philosophical, and artistic traditions to Arabic sources which were translated and transferred to Europe during the twelfth century [14]. These processes had been possible because of countless efforts on the part of translators, poets, religious persons (Francis of Assisi, 1181/82-1226), artists, politicians, and authors (Ramon Llull, 1232-1315). The number of other examples illustrating the deep and fundamental impact of humanistic strategies on the well-being of our lives is legion. The imaginary astronaut mentioned above would also confirm that s/he could survive in the void of his/her space travel only because the image of the blue earth was constantly in his/her mind. Without that goal, without hope for life, love, and God, people could not exist. That's the stuff the humanities are all about, both today and in the future. Of course, we all must first think of how to survive, how to get food, water, and shelter, as Bertolt Brecht emphasized so powerfully in his Threepenny Opera (1928), "first comes food, then moral." Subsequently, however, once the creature's needs have been met, the heart, the mind, and the soul demand principal attention. We are people not simply because of our human body, but because of our human spirit above all. And we know that this is true, considering that Asian philosophers and poets have more or less reached the same conclusions in this regard as Western, African, Australian, or American thinkers or writers.

\section{References and Notes}

1. The relevant research literature on this topic is immense; see, for instance, Sarah Curtis, Space, Place and Mental Health. Geographies of Health (Farnham, Surrey, England; Burlington, VT: Ashgate, 2010); Walter M Bortz, Next Medicine: The Science and Civics of Health (New York: Oxford University Press, 2011); Available online: http://en.wikipedia.org/wiki/ Mens_sana_in_corpore_sano (accessed on 7 September 2011).

2. Wilhelm Von Humboldt (1767-1835). Prospects: The Quarterly Review of Comparative Education; XXIII, no. 3/4, 613-623; Available online: http://www.ibe.unesco.org/fileadmin/ user_upload/archive/publications/ThinkersPdf/humbolde.PDF (accessed on 7 September 2011).

3. For international perspectives, see Albert Rolls, International Perspectives on Education. Reference Shelf, 79, 4 ([Bronx, NY]: H.W. Wilson Co., 2007). As to liberal arts, see Bruce A. Kimball, Orators \& Philosophers: A History of the Idea of Liberal Education (New York: Teachers College, Columbia University, 1986); Gregory S.Prince, Teach Them to Challenge Authority: Educating for Healthy Societies (New York: Continuum, 2008).

4. Wolfram von Eschenbach: Parzival and Titurel. Trans. with Notes by Cyril Edwards. With an Introduction by Richard Barber. Oxford World's Classics. Oxford University Press: Oxford, UK, 2006; Book XVI, section 795, p. 333. 
5. Available online: http://artmuseum.arizona.edu/exhibitions/Nottebohm_Andreas.shtml (accessed on 7 September 2011).

6. Available online: http://www.360cities.net/image/gotthard-tremola-switzerland\#0.00,0.00,70.0 (accessed on 7 September 2011).

7. Available online: http://de.wikipedia.org/wiki/Gotthardpass (accessed on 7 September 2011).

8. Available online: http://en.wikipedia.org/wiki/Ralph_Waldo_Emerson (accessed on 7 September 2011).

9. Available online: http://www.albrecht-durer.org/Durer\%27s-Mother-large.html (accessed on 7 September 2011).

10. Wellbery, D.E. Faust and the Dialectic of Modernity. In A New History of German Literature; Ryan, J., Ed.; The Belknap Pres of Harvard University Press: Cambridge, MA, USA, London, UK, 2004; pp. 546-551.

11. Available online: http://www.poetryintranslation.com/PITBR/German/FaustIScenesIVtoVI.htm (accessed on 7 September 2011).

12. Nussbaum, M. Cultivating Humanity: A Classical Defense of Reform in Liberal Education; Harvard University Press: Cambridge, MA, USA, 1997.

13. I Have a Dream. Available online: http://en.wikipedia.org/wiki/I_Have_a_Dream; http://ia700402.us.archive.org/29/items/MLKDream/MLKDream_64kb.mp3 (accessed on 7 September 2011).

14. Une conquête des savoirs: Les traductions dans l'Europe latine (fin du XIe siècle milieu du XIIIe siècle). Colloque organisé à la Fondation Singer-Polignac le jeudi 27 novembre 2008. Actes édités par Max Lejbowicz. Rencontres Médiévales Européennes, 9 (Turnhout: Brepols, 2009).

(C) 2011 by the authors; licensee MDPI, Basel, Switzerland. This article is an open access article distributed under the terms and conditions of the Creative Commons Attribution license (http://creativecommons.org/licenses/by/3.0/). 